\title{
PRESENTACIÓN DEL VOLUMEN
}

Es un placer ofrecer al lector el vigésimo séptimo volumen de la revista Estudios Hispánicos, que mayoritariamente recoge los resultados de las investigaciones de hispanistas de varios países europeos presentados en dos encuentros científicos que se celebraron en Polonia en el año 2017.

El primer congreso titulado Cultura y oralidad: la negociación entre la tradición y la transculturalidad en las lenguas minorizadas fue organizado en la Universidad de Varsovia por Maria Boguszewicz, quien coordina conjuntamente el presente volumen con Justyna Ziarkowska. El tema del congreso se centró en la relación entre las culturas de las lenguas cooficiales de la Península Ibérica y sus respectivas tradiciones orales, que se han convertido en un bastión a la hora de preservar sus rasgos frente a las formas de comunicación masivas que tienden a diluirlas en un mundo cada vez más globalizado. Sin embargo, el concepto de tradición al que nos referimos en la presente publicación no es ni mucho menos esencialista. Entendemos la tradición como el resultado de un proceso evolutivo inacabado con dos polos dialécticamente vinculados: la continuidad recreada y el cambio. Por otra parte, las nuevas tecnologías y el espacio virtual de la Red constituyen, junto con los medios sociales y otros modos digitales de comunicación y de convivencia, todo un reto para redefinir la oralidad de estas nuevas formas de construcción de identidades colectivas inestables y temporales. En definitiva, con este aporte pretendemos examinar y presentar una panorámica sobre la oralidad en las culturas minorizadas de la Península Ibérica analizando sus peculiaridades, actualidad y retos desde una perspectiva interdisciplinar.

Dado que la lengua es un elemento clave de la cultura, de sus formas orales y de la tradición, empezamos el número con el artículo de José Manuel Dopazo Entenza, que analiza los hábitos lingüísticos de tres generaciones de la comunidad de habla de la Illa de Ons. Valentyna Kotenko, en su texto sobre Korrika, relaciona el discurso deportivo con la situación lingüística de Euskadi. En cambio, Bartosz Dondelewski cuenta su experiencia como investigador en la comunidad de fala de Xálima en el contexto de la identidad tanto de él mismo como de los entrevistados. En el artículo siguiente, António Bárbolo Alves prueba la capacidad de la lengua mirandesa, en sus formas orales, de traspasar las fronteras de la Terra de Miranda. En un sentido parecido, Marta Pawlikowska, recurriendo al ejemplo de Luar na Lubre, argumenta que la tradición oral necesita la música para su transmisión y difusión adquiriendo 
unas formas artísticas híbridas. En el caso de la cinematografía, Magdalena Anna Gajewska investiga cómo la mitología vasca está presente en la historia oral y de qué forma el cine refleja esta historia en el Guardián invisible de Fernando González Molina. En cuanto al formato televisivo, el artículo de Tomàs Vibot Railakari presenta la creación biográfica de Mateu Mir Albertí según las entrevistas emitidas en el programa de la televisión autonómica de las Islas Baleares. Pasando a la expresión literaria, incluimos el texto de Artur Garcia Fuster, quien trata la oralidad como la base de la literatura analizando la narrativa de Jesús Moncada. En cambio, Diego Rivandulla Costa se refiere en su artículo a la memoria oral y su capacidad de resistencia manifestada en las novelas. Cristian Cámara Outes aporta una reflexión teórica acerca de la aplicación de las ideas de Boris Eikhenbaum a las literaturas minorizadas. Cerramos la sección "Cultura y oralidad" con la presentación de Pilar Mega Rodríguez y Belén Mainer Blanco sobre un Legendario Literario Hispánico del siglo XIX en línea como una propuesta aplicable también a las comunidades lingüísticas minorizadas de la Península Ibérica.

El segundo encuentro científico del que se nutre el siguiente bloque de trabajos del presente volumen tuvo lugar en noviembre de 2017 en Wrocław. Gracias al impulso de la dirección (Beata Baczyńska) del Departamento de Filología Románica de la Universidad de Wrocław (Polonia) y la coordinación de sus investigadores (Marcin Kurek, Aleksander Trojanowski) se logró poner en marcha la colaboración con la Universidad La Sabana (Colombia) representada por Bogdan Piotrowski, académico colombiano y decano de la Facultad de Filosofía y Ciencias Humanas de la institución bogotana. El fruto de esta cooperación fue el XIII Coloquio Internacional "Literatura hispanoamericana y sus valores", que reunió a una veintena de investigadores de Hispanoamérica y Europa del Este. El motivo de estos encuentros, que se celebran anualmente desde 2010 en diferentes lugares, es el bicentenario de la Independencia. La edición del 2017 estaba dedicada a las relaciones entre Europa y América Latina. Este volumen acoge algunas de las contribuciones leídas en Wrocław. Rafael Jiménez Cataño, de la Universidad Santa Croce de Roma, revisa las referencias que Octavio Paz hace al período de la Nueva España en sus obras ensayísticas y cómo describe la identidad de aque1la sociedad novohispana. El trabajo del investigador checo Jan Mlčoch, de la Universidad de Ostrava, versa sobre diferentes rasgos de la postmodernidad en la novela El mundo alucinante del escritor cubano Reinaldo Arenas. Finalmente Amán Rosales Rodríguez, de la Universidad Adam Mickiewicz de Poznań, confronta en su análisis las opiniones de dos ensayistas argentinos - Ezequiel Martínez Estrada y Jorge Luis Borges - sobre la recepción hispanoamericana de la tradición cultural europea.

En la sección "Varia" hemos incluido textos fuera del ámbito de los dos congresos citados. Se trata de la aportación de Marcin Kurek, quien aborda el tema del predominio de los códigos visuales para el desarrollo de la poesía moderna, analizando la obra de Joan Brossa y Vladimir Nabokov. Aleksander 
Trojanowski explora el motivo de la cetrería en el contexto de la técnica narrativa de la novela Nocturno de Chile de Roberto Bolaño, que le permite interpretarla como una deconstrucción del testimonio como un modo de enunciación auténtico. Anna Wendorff analiza cómo construyen sus narraciones los emigrantes polacos en las misiones argentinas basándose en la entrevista que la investigadora llevó a cabo con una representante de aquella comunidad.

Los diecisiete estudios del tomo vienen enmarcados por dos secciones tradicionales de nuestra revista: por un lado "Crónica del hispanismo" y por el otro "Reseñas y notas de lectura". En la primera ofrecemos la triste noticia de la muerte de Florian Śmieja, gran hispanista, doctor honoris causa por la Universidad de Wroclaw, condecorado por el rey Felipe VI con la Cruz de Encomienda de la Orden de Isabel Católica, y durante varios años miembro del Consejo Científico de nuestra revista. Se recoge asimismo en este apartado la noticia jubilosa sobre la participación de hispanistas relacionados con Estudios Hispánicos en el acto del homenaje al hispanismo internacional organizado por la fundación Duques de Soria. La sección "Reseñas y notas de lectura" nos pone al corriente de algunas novedades editoriales del hispanismo polaco así como de los libros extranjeros dedicados a las relaciones polaco-hispanas y polaco-lusitanas, e incluso caboverdianas.

Por último queremos mostrar nuestro profundo agradecimiento tanto al Consejo Asesor que ha colaborado en este número como a todos los autores.

Maria Boguszewicz (Uniwersytet Warszawski)

Justyna Ziarkowska (Uniwersytet Wrocławski) 